\title{
Effects of Co-Ingestion of AAKG and HMB on Jumping Performance in Young Track and Field Athletes
}

\section{Piotr Kaczka ( $\sim$ kaczor81@o2.pl )}

Akademia Wychowania Fizycznego imienia Jerzego Kukuczki w Katowicach https://orcid.org/00000002-1730-6335

\section{Amit Batra}

Akademia Wychowania Fizycznego imienia Jerzego Kukuczki w Katowicach

\section{Katarzyna Kubicka}

Akademia Wychowania Fizycznego imienia Jerzego Kukuczki w Katowicach

\section{Marcin Maciejczyk}

Akademia Wychowania Fizycznego im Bronislawa Czecha

\section{Rafał Jastrząb}

Akademia Wychowania Fizycznego imienia Jerzego Kukuczki w Katowicach

\section{Edyta Kopera}

Akademia Wychowania Fizycznego imienia Jerzego Kukuczki w Katowicach

\section{Justyna Bira}

Akademia Wychowania Fizycznego imienia Jerzego Kukuczki w Katowicach

\section{Tomasz Zając}

Akademia Wychowania Fizycznego imienia Jerzego Kukuczki w Katowicach

\section{Research article}

Keywords: training camp supplementation, medium distance runners, $\beta$-hydroxy- $\beta$-methylbutyrate, HMB, L-arginine a-ketoglutarate, AAKG, countermovement jump, CK-creatine kinase, LDH - lactate dehydrogenase.

Posted Date: August 12th, 2020

DOI: https://doi.org/10.21203/rs.3.rs-55557/v1

License: (c) (1) This work is licensed under a Creative Commons Attribution 4.0 International License. Read Full License 
1 Effects of co-ingestion of AAKG and HMB on jumping performance in young track and field athletes

3 Piotr Kaczka $^{\mathrm{a}^{*}}$, Amit Batra ${ }^{\mathrm{a}}$, Katarzyna Kubicka ${ }^{\mathrm{a}}$, Marcin Maciejczyk ${ }^{\mathrm{b}}$, Rafał 4 Jastrząb $^{a}$, Edyta Kopera ${ }^{a}$, Justyna Bira ${ }^{a}$, Tomasz Zając ${ }^{a}$,

5 a Academy of Physical Education in Katowice, ul. Mikołowska 72a, 40-065 Katowice, 6 Poland

$7 \quad{ }^{b}$ University of Physical Education in Krakow, al. Jana Pawła II 78, 31-571 Kraków, Poland

$8 \quad *$ Corresponding author: Piotr Kaczka, e-mail: kaczor81@o2.pl 


\section{Abstract}

Background: The aim of the study was to determine the effect of simultaneous supplementation of $\beta$-hydroxy- $\beta$-methylbutyrate and L-arginine $\alpha$-ketoglutarate on lower limb power and muscle damage in medium distance runners aged $15.3( \pm 0.9)$ years old.

Methods: The study group consisted of 40 volunteers (men and women) aged 14-17 (juniors and younger juniors) who have been practicing medium distance running for at least two years. The study followed a randomised, double-blind, placebo-controlled design. All subjects attended a familiarisation session on day 0 before the test commenced. The subjects were randomly divided into two groups: supplements group and placebo group. A similar training cycle protocol was used in both groups. Daily sRPE values, countermovement jump measurement as well as blood creatine kinase and lactate dehydrogenase were measured during 12-day training period.

Results: After the end of the training cycle, a significant $(p=0.002)$ decrease in the countermovement jump (CMJ) height was found in the placebo group when compared to the baseline measurement. In the supplements group, there was no decrease in the countermovement jump value, which was close to the baseline level after the end of the training cycle ( $p>0.05)$. During the 12-day training period, statistically significant changes in creatine kinase and lactate dehydrogenase levels were recorded between the supplements and placebo groups; its concentration increased during the training weeks similarly, and decreased on rest. All the changes were at a comparable level in both groups. The research results indicate that the supplement combination used in the supplements group prevented a reduction in the CMJ values. In contrast to supplements group, in the placebo group, the CMJ changes were statistically significant: a noticeable $(\mathrm{p}=0.002)$ decrease in $\mathrm{CMJ}$ was noted between the baseline measurement and the 6th measurement. The well-being of the subjects from both 
groups changed significantly during the training period, and the intergroup differences in the mood level were similar and not statistically significant.

Conclusions: The results of this study indicate that the daily co-supplementation with $\beta$-hydroxy- $\beta$-methylbutyrate (6 g) and L-arginine $\alpha$-ketoglutarate (8 g) during the 12-day intensive training camp may prevent deterioration of lower limb muscle power measured by the CMJ test in the well-trained youth track and field athletes.

Keywords: training camp supplementation, medium distance runners, $\beta$-hydroxy- $\beta$ methylbutyrate, HMB, L-arginine $\alpha$-ketoglutarate, AAKG, countermovement jump, CK- creatine kinase, $\mathrm{LDH}$ - lactate dehydrogenase.

\section{Background}

Many athletes are still looking for methods which can significantly enhance their performance. Consequently, supplements, especially those taken before a workout, are becoming an increasingly popular class of dietary supplements among athletes. The prevalence of supplementation among athletes has been estimated at 37 to $89 \%$ (1). Beta-hydroxy-betamethylbutyrate (HMB) and L-arginine $\alpha$-ketoglutarate (AAKG) remain among the most popular dietary supplements on the market.

$\beta$-hydroxy- $\beta$-methylbutyrate (HMB) is one of the best-tested compounds found in dietary supplements and ergogenic aids for physically active people. HMB is a derivative of leucine that has been extensively studied for protein metabolism, insulin activity or post-workout recovery.

L-Arginine (ARG) is a conditionally essential amino acid whose primary function is the participation in protein synthesis and ammonia detoxification. It is also involved in several other functions related to its metabolism to biologically active particles, such as nitric oxide, creatine, agmatine, glutamine, ornithine, polyamines or citrulline (2). 
When it comes to the effect of HMB on anaerobic capacity, several previous studies described the effectiveness of HMB-Ca (salt form) supplementation on muscular strength and body composition. Niessen and co-workers (3) showed that $1.5 \mathrm{~g} /$ day and $3.0 \mathrm{~g} /$ per day of HMB taken by untrained males every day during a 3-week resistance training program caused that they were more efficient in a 1-RM testing protocol when compared to the placebo group. Also, the total strength increased significantly by $13 \%(1.5 \mathrm{~g} \mathrm{HMB} / \mathrm{d})$ and $18.4 \%(3.0 \mathrm{~g} \mathrm{HMB} / \mathrm{d})$ in the subjects taking HMB when compared to placebo, and this dependency was HMB dosedependent. Asadi et al. (4) during the six-week study also demonstrated the positive influence of HMB-FA supplementation on strength and power performance compared to the placebo group.

Panton et al. (5) demonstrated that a 4-week supplementation with $3 \mathrm{~g}$ of HMB per day during resistance training increased 1-RM strength (only in the HMB-group) in the upper-body exercises. No differences in the lower body strength between the placebo and the HMB groups were observed. In contrast to this research, Wilson et al. (6) during their 12-week study on 20 trained male subjects who were given $3 \mathrm{~g}$ of HMB per day observed strength increases in the squat and bench press compared to the placebo group. Also some advantageous changes in body mass, FFM, BF, and quadriceps thickness were observed in the subjects supplemented with HMB.

What is certainly not less interesting, some researchers have investigated the effectiveness of HMB supplementation on anaerobic power (i.e. Wingate test) and countermovement jump (CMJ) performance $(6 ; 7)$. The study conducted by Wilson et al. (6) noticed an improvement in Wingate test results and CMJ performance, while Kreider et al. (2000) did not observe any enhancement in 12 x 6 cycle ergometer interval sprint tests..

Durkalec-Michalski et al. (8) reported that after 12 weeks of supplementation with $3 \mathrm{~g}$ of HMB per day, in comparison to the placebo treatment, a significant increase in the anaerobic 
peak power, average power, maximum speed, and post-exercise lactate concentration was recorded during the Wingate test on a cycle ergometer. Moreover, taking into consideration the initial values, the supplementation of HMB increased the peak power output, average power, maximum speed and post-exercise lactate concentrations, with a simultaneous reduction of the time needed to achieve peak power, compared to the placebo group.

There is also some evidence that ARG supplementation could have a beneficial influence on anaerobic capacity. Yavuz et al. (9) examined the significance of a single dose of L-arginine $\left(1.5 \mathrm{~g} \cdot 10 \mathrm{~kg}^{-1}\right.$ body weight) given to 9 male national and international level wrestlers after a 12-hour (night) fast. The athletes performed an incremental bicycle ergometer test to exhaustion during which several parameters (oxygen consumption, heart rate and plasma lactate levels) were measured. The results showed that the significant difference was observed in time to exhaustion which was prolonged in the L-arginine group $(1386.8 \pm 69.8 \mathrm{~s})$ when compared to placebo $(1313 \pm 90.8 \mathrm{~s})(\mathrm{p}<0.05)$.

Bailey et al. (10) studied the effects of a 3-day supplementation with $6 \mathrm{~g} / \mathrm{d}$ of L-arginine (dissolved in $500 \mathrm{ml}$ of water) which was taken by 9 trained, healthy active men 60 min before exercise on a cycle ergometer. The participants were requested to complete 6-minute cycling bouts with a moderate intensity; the last cycle was continued until failure, and it was used as a measure of exercise tolerance. There was significant increase in plasma nitrite and time to task failure in the ARG group when compared to the placebo group. In both groups, there was also significantly lower oxygen consumption $\left(\mathrm{VO}_{2}\right)$ during moderate-intensity cycle exercise; the $\mathrm{VO}_{2}$ slow component amplitude was reduced during severe-intensity exercise, favouring the ARG group.

Campbell et al. (11) reported significant increases in the 1-RM strength and anaerobic power (Wingate test) among 35 resistance-trained healthy males after supplementation of $12 \mathrm{~g}$ 
of AAKG (6 $\mathrm{g}$ of L-arginine) per day for eight weeks. The authors observed a significant increase in the peak power in the AAKG group in comparison to the placebo group.

Mor et al. (12) observed no statistically significant difference before and after supplementation between the experimental ( $6 \mathrm{~g}$ of ARG) and the placebo (6 g of wheat bran) groups consisting of 28 active male football players who played in amateur leagues during the 14-day research. Nevertheless, the post supplementation recovery lactic acid levels showed a more rapid reduction in the experimental group when compared to the placebo one. A similar relationship was observed for the indicator of muscle injury expressed by a decreased level of LDH enzymes in the ARG group. All this suggests that the supplementation with L-arginine helps not only to excrete lactic acid from the body more effectively but also increases muscle recovery by lowering the level of $\mathrm{LDH}$ enzymes when compared to the placebo group.

The use of L-arginine in post-workout recovery was also raised in the research of McConell et al. (13), who submitted 9 endurance-trained males to a steady-state cycle ergometer exercise for 120 minutes. During the last 60 minutes of cycling, the subjects were given either a placebo or L-arginine $\mathrm{HCl}(30 \mathrm{~g}$ at $0.5 \mathrm{~g} / \mathrm{min})$ intravenously. ARG infusion significantly increased skeletal muscle glucose clearance when compared to placebo, without increasing plasma insulin concentration. The authors suggested that L-arginine increased NO production, which then elevated muscle glucose uptake and might helped muscle recovery.

Most ARG studies indicate that this amino acid has no or little effect on anaerobic capacity. However, some experiments show directional activity in this area, mainly due to the presence of NO (nitric oxide) deriving from ARG, which appears to be useful for protecting muscle from being injured and aids their recovery. Similar, though much better described results are associated with HMB and the enhancement of the sarcolemma integrity properties via higher availability of cytosolic cholesterol (14), inhibiting protein degradation (15), decreasing cell apoptosis (16), increasing protein synthesis (mTOR pathway;14, 15), stimulating the growth 
hormone (GH)-insulin-like growth factor-1 (IGF-1) axis and enhancing muscle stem cells proliferation and differentiation (16).

It would be interesting to know whether these two popular dietary supplements used simultaneously would show an additive effect, especially noticeable during intense anaerobic workouts. Meanwhile, it should be emphasised that this combination of supplements has not been previously studied.

Therefore, the purpose of this study was to check whether two popular supplements, $\beta$-hydroxy- $\beta$-methylbutyrate (HMB) and L-arginine $\alpha$-ketoglutarate (AAKG), would have beneficial influence on blood biochemical parameters (creatine kinase- CK and lactate dehydrogenase- LDH), lower limb strength and power and the subjective perception of the severity of effort and well-being in the group of young medium distance runners during a 12day intensive preparatory camp. We hypothesise that the combination of these two compounds can have an additive effect for examined factors, than that observed during consuming HMB and AAKG separately.

\section{Methods}

\section{Study design}

Following an explanation of all procedures, risks, and benefits associated with the study, each subject gave his written consent before he participated in the study. The study was approved by the Ethical Committee of the Academy of Physical Education in Katowice (Katowice, Poland) and conformed to the ethical requirements of the 1975 Helsinki Declaration. The subjects were also required to refrain from taking any nutritional supplements or ergogenic aids for the two weeks preceding the study. They were also asked to not to take any additional supplements during the duration of the study. The volunteers gave their written consent to participate in the study. 
attended a familiarisation session on day 0 before the test commenced. The subjects were also

session, the participants were shown and explained the rules for completing a well-being

questionnaire and a session RPE (sRPE) protocol; they were also informed about planned tests during the entire 12-day period (Table 1).

165

\begin{tabular}{|c|c|c|c|c|c|c|c|}
\hline & $\begin{array}{l}\text { familiarisation } \\
\text { / baseline } \\
\text { values }\end{array}$ & & & & & & \\
\hline & day 0 & day 1 & day 2 & day 3 & day 4 & day 5 & day 6 \\
\hline Blood samples & & + & & + & & + & \\
\hline CMJ & + & + & + & + & + & + & + \\
\hline $\begin{array}{l}\text { well-being } \\
\text { questionnaire }\end{array}$ & + & + & + & + & + & + & + \\
\hline sessionRPE & & + & + & + & + & + & + \\
\hline & & day 7 & day 8 & day 9 & day 10 & day 11 & day 12 \\
\hline Blood samples & & + & & + & & + & \\
\hline CMJ & & + & + & + & + & + & + \\
\hline $\begin{array}{l}\text { well-being } \\
\text { questionnaire }\end{array}$ & & + & + & + & + & + & + \\
\hline sessionRPE & & + & + & + & + & + & + \\
\hline
\end{tabular}

Table 1. Daily schedule of tests performed during 12 days of the experiment. Day 0 was dedicated to familiarising with the research protocols, establishing the baseline values for CMJ and filling in the questionnaire of well-being. 


\begin{tabular}{|c|c|c|c|}
\hline Time & Activity & $\begin{array}{c}\text { Supplements group } \\
\text { (SUP) }\end{array}$ & $\begin{array}{c}\text { Placebo group } \\
\text { (PL) }\end{array}$ \\
\hline \multirow{3}{*}{ 6:00 - 6:15 } & $\begin{array}{l}\text { Blood sample } \\
\text { collections }\end{array}$ & + & + \\
\hline & SUP/PL & $\begin{array}{l}2 \text { caps } \mathrm{AAKG} \\
+2 \text { caps } \mathrm{HMB}\end{array}$ & 4 caps placebo \\
\hline & $\begin{array}{l}\text { Well-being } \\
\text { questionnaire }\end{array}$ & + & + \\
\hline $6: 15$ - $6: 45$ & Morning warm-up & + & + \\
\hline 6:45 - 7:00 & $\begin{array}{l}\text { Counter movement } \\
\text { jump test }\end{array}$ & + & + \\
\hline 7:00 - 8:00 & Breakfast & & \\
\hline 9:00 & SUP/PL & $\begin{array}{c}3 \text { caps } \mathrm{AAKG}+ \\
2 \text { caps } \mathrm{HMB}\end{array}$ & 5 caps placebo \\
\hline \multirow[t]{2}{*}{ 10:00 - 12:00 } & Training 1 & + & + \\
\hline & sessionRPE 1 & + & + \\
\hline 13:00 - 14:00 & Lunch & & \\
\hline 15:00 & SUP/PL & $\begin{array}{l}3 \text { caps } \mathrm{AAKG} \\
+2 \text { caps } \mathrm{HMB}\end{array}$ & 5 caps placebo \\
\hline \multirow[t]{2}{*}{ 16:00 - 18:00 } & Training 2 & + & + \\
\hline & sessionRPE 2 & + & + \\
\hline 19:00 - 20:00 & Dinner & & \\
\hline
\end{tabular}

Table 2. Daily regimen of meals, supplementation and frequency of training as well as samples and data collection during the 12-day study period.

\section{Subjects}

The study group consisted of 40 volunteers (men and women) aged 14-17 (juniors and younger juniors) who have been practicing medium distance running for at least two years; the subjects were randomly assigned to the placebo (PL) or supplements (SUP) group. The study was completed by 15 subjects from the placebo group, including 7 men $(15.1 \pm 1.2$ y; $64.6 \pm 7.8 \mathrm{~kg}$; $171.4 \pm 6.6 \mathrm{~cm})$ and 8 women $(15.0 \pm 1.2 \mathrm{y} ; 52.6 \pm 5.5 \mathrm{~kg} ; 158.9 \pm 5.8 \mathrm{~cm})$. In the supplementation group (SUP), 19 subjects completed the study, including 7 men $(15.0 \pm 1.0 \mathrm{y}$; $66.0 \pm 3.9 \mathrm{~kg} ; 173.0 \pm 7.3 \mathrm{~cm})$ and 12 women $(15.3 \pm 1.3 \mathrm{y} ; 50.6 \pm 3.8 \mathrm{~kg} ; 156.1 \pm 7.2 \mathrm{~cm})$. 
191

192

193

194

195

196

197

198

\section{Supplementation}

The participants were randomly divided into two groups. The placebo group (PL) was administered hard, gelatine capsules with microcrystalline cellulose. In contrast, the supplements group (SUP) was given a combination of two supplements which are commercially marketed as HMB 1250 Mega Caps ${ }^{\circledR}$ (Olimp Laboratories, Debica, Poland; HMB) of which one capsule contains $1250 \mathrm{mg}$ of calcium salt of $\beta$-hydroxy- $\beta$-methylbutyrate which equals $1000 \mathrm{mg}$ of pure $\beta$-hydroxy- $\beta$-methylbutyrate and AAKG 1250 Extreme Mega Caps ${ }^{\circledR}$ (Olimp Laboratories, Debica, Poland; AAKG) of which one capsule contains $1250 \mathrm{mg}$ of L-arginine $\alpha$ ketoglutarate which equals $813 \mathrm{mg}$ of L-arginine. Each participant took them three times a day approximately $15 \mathrm{~min}$ before early morning warm-up and then $60 \mathrm{~min}$ before the first and the second training. A set dose of the supplements or placebo was administrated as described in Table 2 below. Each dose was taken with $200 \mathrm{ml}$ of still water. No subjects reported any adverse events or side effects following the ingestion of the supplement or placebo.

\section{Training}

\section{Early morning warm-up:}

Standard warm-up started with 10 min jogging at $60 \%-75 \%$ of maximal heart rate. After this task, the participants performed various dynamic exercises (arm swing, internal/external leg rotation, hip flexion/extension/ abduction/adduction/ hip rotation, knee rotation, and ankle rotation) followed by $15 \mathrm{~min}$ jogging.

\section{Main training units}

The training cycle comprised of general preparation units, including off-road running games, as well as specific units. 
Each training unit consisted of four parts: introduction (presenting the training goal and tasks, dividing into smaller training groups: 3-5 min), initial (warm-up jogging, dynamic stretching for 20-25 min), main (achieving the fundamental training goal for 75-80 min) and final (easy jog, flexibility exercises for $15 \mathrm{~min})$.

The training units were identically arranged for both groups and had the same volume. Each day, the selected training unit (morning or afternoon) was carried out with a greater load. Session RPE was used to describe the training load of each workout, as presented below. Similar levels of session RPE were observed in the athletes in both groups (SUP and PL). During the boot camp, both groups (PL and SUP) trained 36 times in total. The total training time was 54 hours per athlete from each group. The seventh day of the camp was partially a rest period — only one, low-intensity training took place then.

\section{Fatigue and well-being assessment}

The day before the camp began, as well as every morning during its duration, a psychometric survey was carried out before the start (17). The survey comprised of five questions related to perceived fatigue, sleep quality, general muscle soreness, stress levels and mood; each question was scored on a 5-point scale (with 1 and 5 representing poor and very good wellness ratings, respectively) (18). Using the questionnaire, the participants made a subjective assessment of overall fatigue and well-being.

\section{Training load assessment}

The session-RPE (sRPE) method takes into consideration the intensity and the duration of the training session to calculate the "training load" (TL; 19). The training load (arbitrary units) was calculated for all subjects as total training duration $(\mathrm{min}) \times$ session rating of 
perceived exertion (RPE, CR10 modified Borg's scale), collected within 10 min of completing each training session (20).

All athletes were familiarised with the CR-10 scale according to standard procedures (21) before beginning to collect reliable measurements. Immediately after the end of each training unit, each participant reported the subjective value of the session RPE, which was recorded by the coach. The mean value of the two daily sRPE values was used for statistical calculations.

\section{Countermovement jump}

The countermovement jump measurements were taken using the Optojump Next system (Microgate, Bolzano, Italy) — an optical measuring system used in time-based tests. For example, the vertical jump height is calculated from the value of this measurement. CMJ is used as an indirect measurement of lower limb power. The measurement was taken daily after the morning warm-up. The starting position was standing upright with the arms placed on the hips to prevent them from swinging. The athletes were instructed to begin with the eccentric phase — make a preliminary downward movement by flexing at their knees and hips to the semisquatting position and immediately perform the highest jump possible (concentric phase). The landing was allowed with normal flexion and the standing still phase in the neutral position was obligatory for 1-2 seconds. Bending the lower limbs before performing the jump causes initial stretching of the muscles, thanks to which more work is done in the concentric phase. Each of the subjects made three countermovement jumps with 1-minute rest between them. The average value of the three jumps was used for calculations.

\section{Biochemical analyses}

Blood samples were taken by qualified medical personnel and used to assess the concentration of the creatine kinase (CK) and lactate dehydrogenase (LDH) enzymes as the 
markers of the level of muscle tissue damage. CK and LDH tests were performed in a laboratory that validated methods for the determination of these particles using biochemical tests (iSTAT® CK-MB (Abbott), and Lactate Dehydrogenase (LDH) ELISA Kit (MyBioSource.com). Blood samples were taken six times (every 48 hours) from a vein in the $\operatorname{arm}(4 \mathrm{ml}$ of blood) in the morning — before a fasted morning warm-up. The participants were instructed to rest for a few minutes in a sitting or lying position and to avoid physical activity immediately before blood samples were to be taken.

The first blood samples were taken in the morning on the first training day (baseline). The results from 6 measurement points were collected.

\section{Statistical analysis}

The changes in the analysed indicators and intergroup differences in the level of the analysed indicators were determined using analysis of variance (ANOVA) with repeated measurements. In the case of significant changes for the main effect $(\mathrm{p}<0.05)$, post hoc analysis was performed using the Tukey test (HSD). Statistical analysis was conducted in the Statistica program (USA). The data in the charts presented is an average with a confidence interval of 0.95 . Any changes in the indicators were considered significant when $\mathrm{p}<0.05$.

\section{Results}

No subjects reported any adverse events or side effects following the ingestion of the supplement or placebo. The level of sRPE at the individual measuring points during the training period in both groups was similar (Fig. 1); it proved that the athletes from both experimental groups had comparable training load during their workout. During the 12-day training period, statistically significant changes in creatine kinase were noted; however, the changes in both groups were at a similar level (Fig. 2). Identical changes were also observed for LDH — the 

statistically significant (Fig. 3).

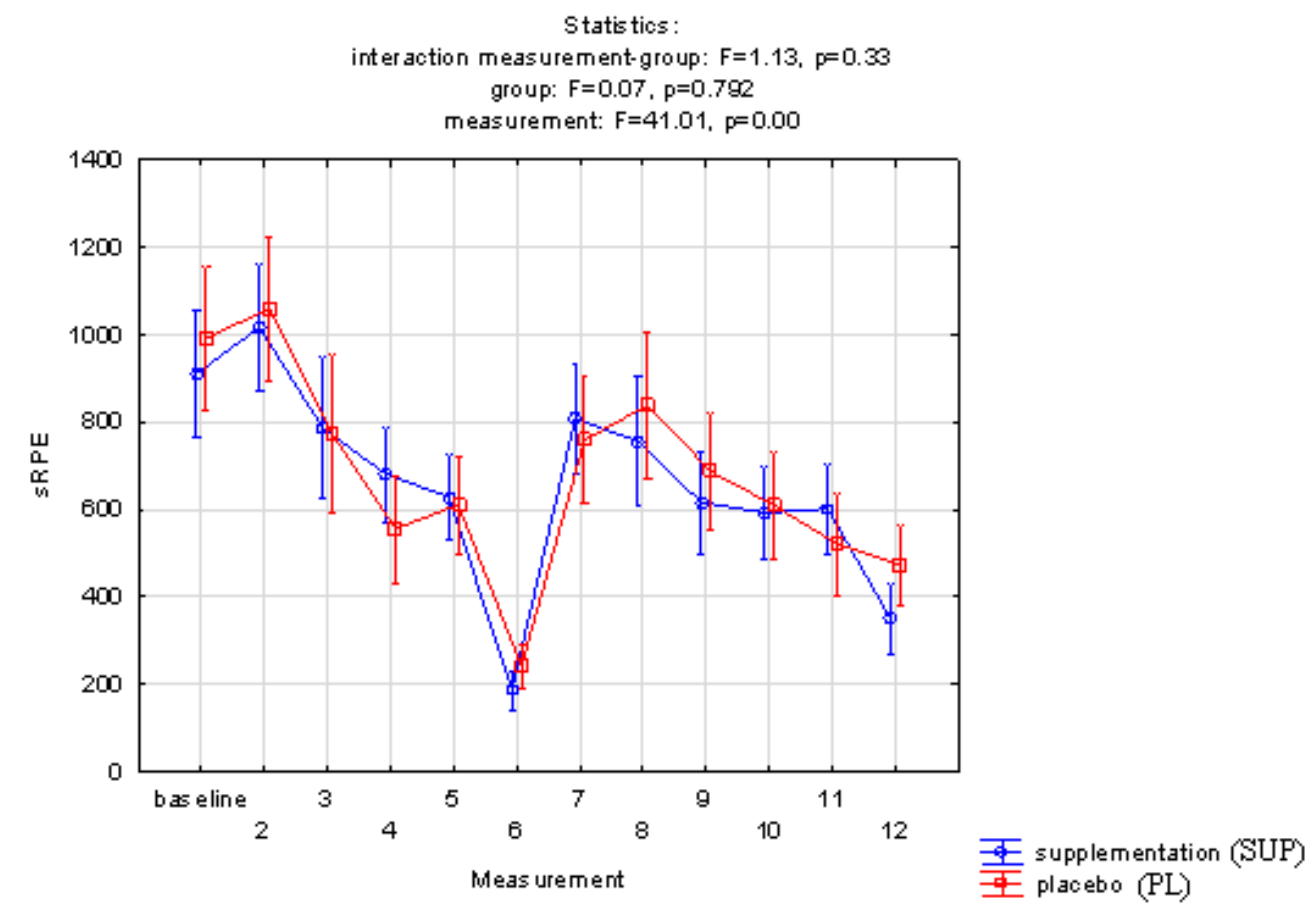

Figure 1. Changes in SRPE during trening in the SUP and PL group

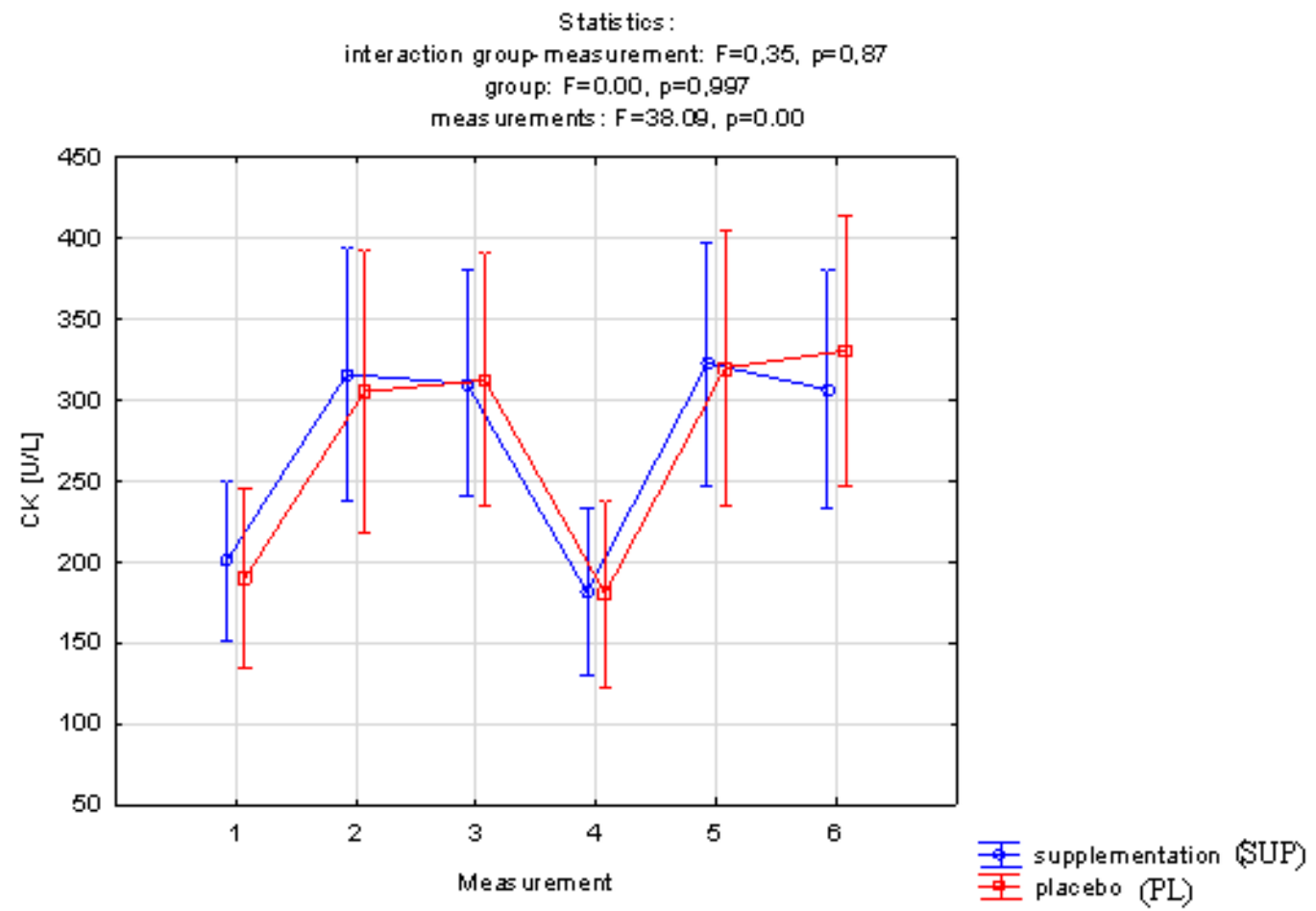

Figure 2. Changes in $\mathrm{CK}$ during training in the SUP and PL group. 


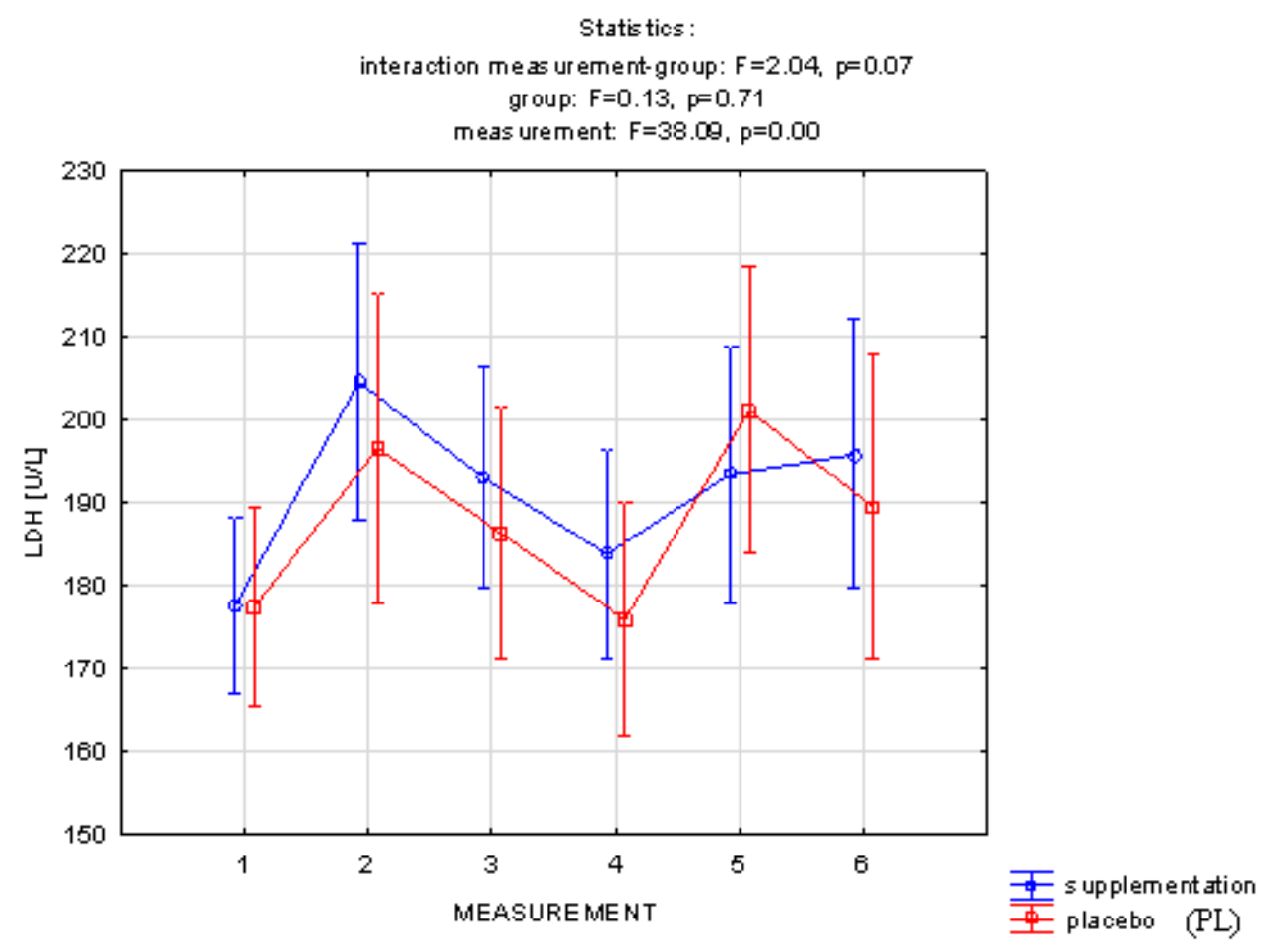

Figures 3. Changes in $\mathrm{LDH}$ during training in the $\mathrm{SU}$ and $\mathrm{PL}$ group.

The changes in CMJ performance in the analysed period were particularly interesting. individual CMJ measurements. In contrast, in the placebo group, the CMJ changes were statistically significant: a noticeable $(\mathrm{p}=0.002)$ decrease in CMJ was noted between the baseline measurement and the 6th measurement. At the same time, a considerable increase in CMJ $(p=0.02)$ between the 6 th and the 7th measurement was also recorded. Finally, when the training period was completed (the last measurement), a significant $(p=0.002)$ decrease in the

CMJ height was observed in the placebo group compared to the baseline measurement. There were no such changes registered in the SUP group; the post-workout CMJ performance was close ( $p>0.05$ ) to baseline (Fig. 4). The well-being of the subjects from both groups changed significantly during the training period, and the intergroup mood differences were similar (Fig. 5). 
Page $\mathbf{1 6}$ of $\mathbf{2 5}$

St atistics:

interaction group-measurement: $F=1.92, p=0.03$

group: $F=0,14, p=0.70$

me as urement: $F=1.93, p=0.04$

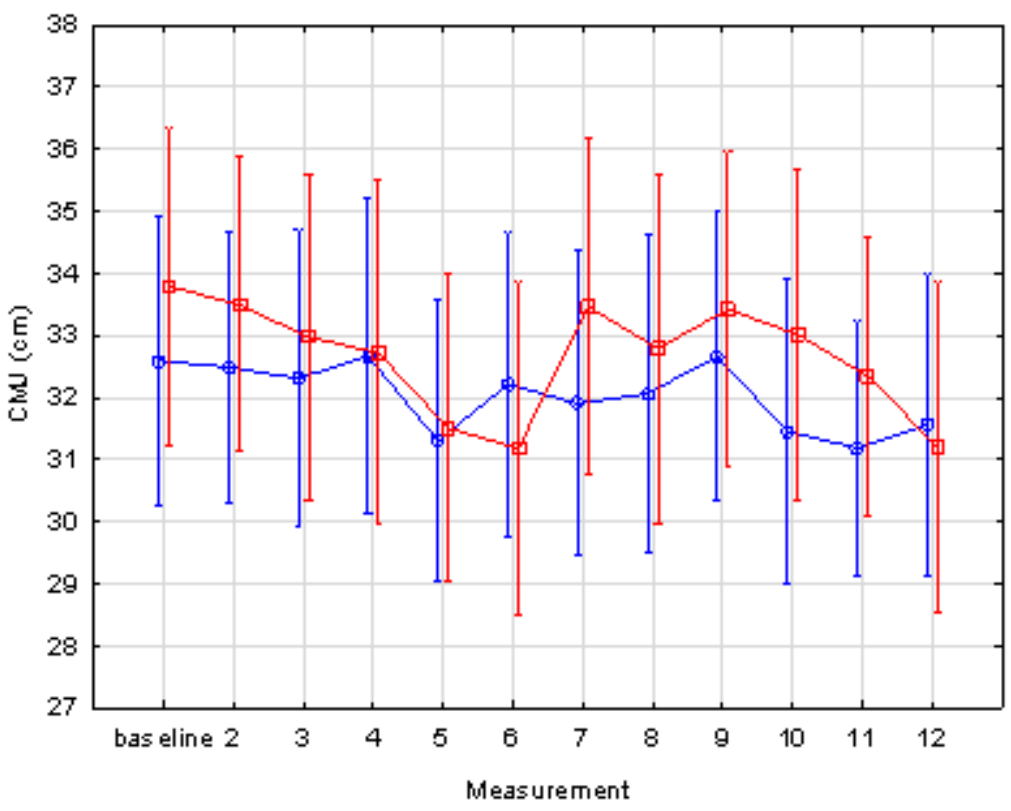

supplementation (SUP)

Figure 4. Changes in CMJ during training in the SUP and PL group.

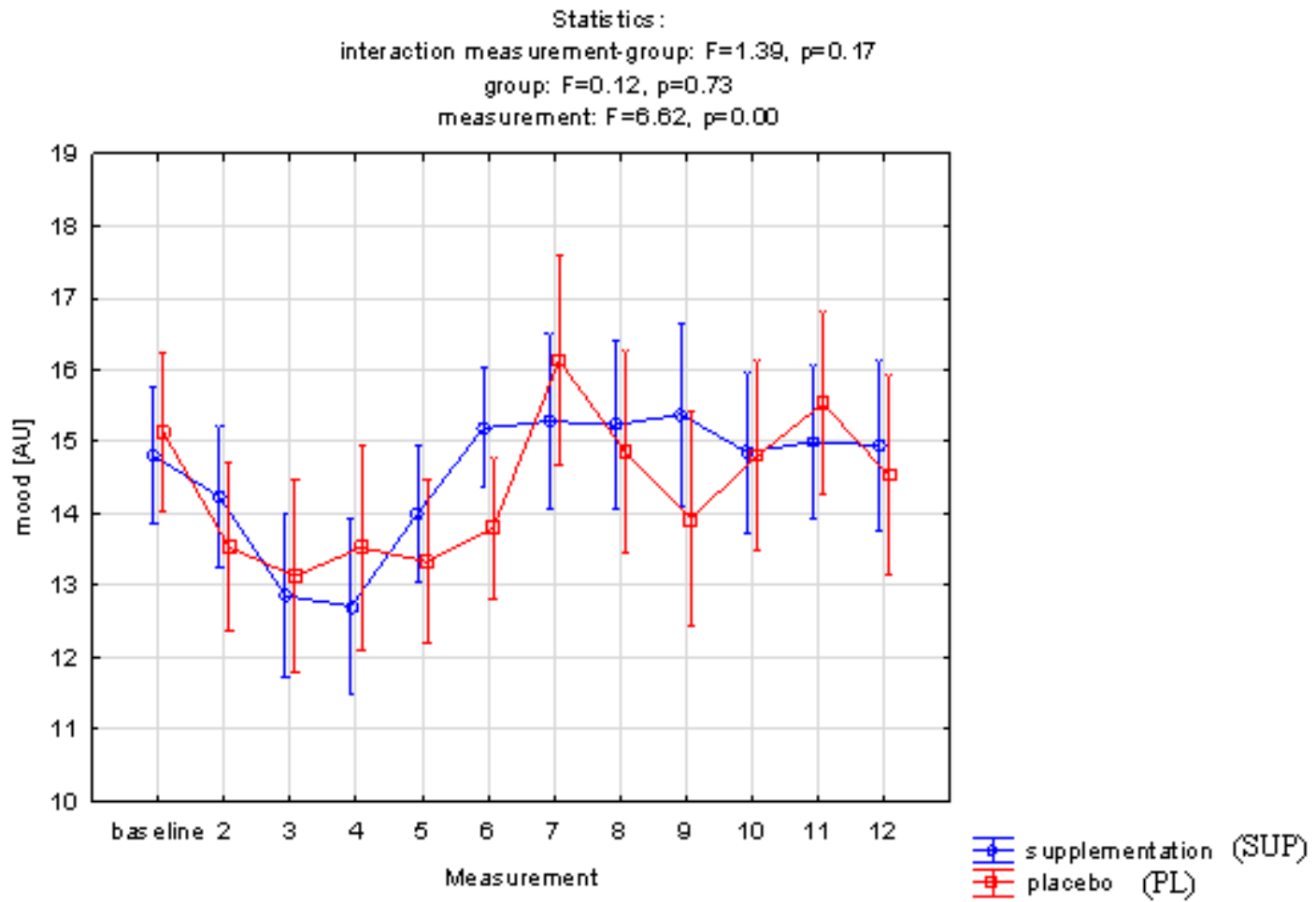

Figure 5. Changes in mood during training in the SUP and PL group 


\section{Discussion}

The purpose of this study was to check whether the intensive use of two popular supplements, $\beta$-hydroxy- $\beta$-methylbutyrate (HMB) and L-arginine $\alpha$-ketoglutarate (AAKG), would reduce muscle damage, increase lower limb muscle power and affect the subjective perception of the effort severity and well-being, during an intensive 12-day preparatory camp in the group of young medium distance runners. Significant intergroup differences in lower limb power are the most important discovery of our research. In the supplements group, no significant fluctuations in muscle power were observed during the follow-up; in contrast, in the placebo group, power changes were statistically significant, and at the end of the boot camp unquestionably lower than before the boot camp started. Such power changes can adversely affect the implementation of the training plan and force the coach to change the training load. HMB and AAKG supplementation meant that the power level remained stable, which should be considered beneficial - it allows you to maintain your planned training loads. The placebo group showed a decrease in the CMJ height in the first days. This outcome could have been a result of increased fatigue due to the implementation of subsequent, intensive units of running training. At the same time, no such trend was observed in the SUP group. Although there were no statistical differences in the training program and the subjective assessment of the training load (similar sRPE), a statistically significant decrease in CMJ was shown only in the placebo group. This phenomenon (a reduction in the CMJ height) was not observed in the SUP group, in which CMJ performance remained relatively stable. The research results indicate that, despite the ineffectiveness of the training used, the combination of the two supplements used in the SUP group prevented the deterioration of the CMJ results, which were observed in the placebo group. It should be emphasised that it was only after the camp ended that power supercompensation was to be expected. It can be then concluded that the supplementation allows us to stabilise the power level and carry out the planned training, without the need to 
correct training loads. Research to date $(22,23,24)$ indicates that during the training period, the CMJ height may either decrease or not undergo significant changes. The authors suggest that this may be a result of fatigue accumulation. The co-supplementation of HMB and AAKG could prevent fatigue accumulation and maintain lower limb strength.

The chemical form of L-arginine used in the study, L-arginine $\alpha$-ketoglutarate, as well as the calcium form of $\beta$-hydroxy- $\beta$-methylbutyrate (HMB), are often used in general foods, dietary supplements and special medical foods. This compound has a long history of use and an excellent safety profile and is a well-tolerated and popular ingredient in dietary supplements for athletes in many countries

To this date, a few possible mechanisms of HMB activity in the human body were proposed. The positive effects of HMB supplementation include enhancing sarcolemma integrity via higher availability of cytosolic cholesterol (14), inhibiting protein degradation (ubiquitin pathway; 15), decreasing cell apoptosis (16), increasing protein synthesis (mTOR pathway; 15, 25), stimulating the growth hormone (GH)-insulin-like growth factor-1 (IGF-1) axis and enhancing muscle stem cells proliferation and differentiation (16).

L-arginine (ARG) based products are used mainly before training, due to the potential mechanism of action of nitric oxide (NO) formed from ARG. NO in muscles is responsible for vascular smooth muscle relaxation, thus improving the supply of oxygen and nutrients to the working muscles, as well as for better drainage of anaerobic energy metabolism (26). Besides, nitric oxide is involved in generating the contraction strength of working muscles by affecting the excitatory-contraction coupling. It is also indicated that ARG supplementation reduces the aerobic cost of physical activity (27). This effect can also be caused by a decrease in the concentration of lactate and ammonia in the bloodstream (28) or an increase in the glucose absorption efficiency by muscle cells (13) to which ARG also contributes. 

a reduction in the muscle cell damage markers and thus indirectly faster post-workout regeneration were expected. The effect of supplementation on lower limb power and the well-

362 being and subjective assessment of the intensity of each training unit declared in the survey (an indirect parameter in the evaluation of muscle cell damage) were also examined. The effects of co-administration of only AAKG and HMB have not yet been described in the literature; however, adding L-glutamine to the mixture (3 g HMB, $14 \mathrm{~g}$ L-arginine, $14 \mathrm{~g}$ L-glutamine) administered for six months to healthy elderly increased their lean muscle mass (29). An important finding is a fact that between the SUP and PL groups, no statistically significant differences in the level of muscle cell damage markers, i.e. CK and LDH, were observed. The lack of statistically significant differences could be caused, among others, by individually variable myocyte stability and the ability to metabolise creatine kinase by the athletes in both groups. In addition, Kupiers (30) concluded that in some cases, serum CK might not directly reflect the extent of muscle cell damage. According to the author, this correlation depends, among others, on the level of sex hormones and individual variability, for example, in FFM (fat-free mass; 30). The possible reason for the lack of any changes in the level of muscle cell damage markers (CK and LDH) could be a short duration of the study and supplementation. Based on the research by Niessen et al. (3), it can be seen that Ca-HMB most effectively inhibits protein degradation in the first two weeks of its use, while a significant reduction in serum CK activity occurs only in the third week after commencing the supplementation. It seems that two weeks of $\mathrm{Ca}-\mathrm{HMB}$ supplementation is the minimum period that is effective in reducing muscle damage.

In this study, AAKG and Ca-HMB were co-administered in the SUP group. $6.5 \mathrm{~g}$ derived from $10 \mathrm{~g}$ AAKG (8 capsules) was the set optimal daily dose of L-arginine. The dosage of $6 \mathrm{~g}$ increased muscular blood flow which was correlated with nitric oxide production (31). 
The highest absorption of L-arginine, approximately $70 \%$, is observed at the dose of $6 \mathrm{~g}(32)$; alas, further dose increments do not change its uptake. A dose of $6 \mathrm{~g}$ of L-arginine taken on an empty stomach may increase the concentration of this amino acid in the blood by more than $330 \%$ within 1 hour. It is recommended in the literature to take products based on arginine and its forms within approx. 60 minutes before planned exercise, especially since the half-life tested at the optimal dose is about 80 minutes (32).

Based on the scientific data, it has been observed that the effect of HMB is dosedependent $(33 ; 34,35)$. In scientific research, the most commonly used doses of HMB include $1.5 \mathrm{~g} / \mathrm{d}, 3 \mathrm{~g} / \mathrm{d}$ or exceptionally $6 \mathrm{~g} / \mathrm{d}$ (36). It is assumed that the optimal model for minimising the damage to the trained muscle is a supplementation protocol of $1 \mathrm{~g}$ of $\mathrm{Ca}-\mathrm{HMB}$ taken three times a day with meals. For athletes who want to reduce the length of post-exercise recovery, it is recommended to consume $3 \mathrm{~g}$ Ca-HMB $60 \mathrm{~min}$ before exercise $(33,35)$.

A study was carried out to check the effect of HMB supplementation on the level of muscle tissue damage markers after endurance exercise (20 km cross-country run). The participants were randomly assigned to a placebo group or a group supplemented with $3 \mathrm{~g} H \mathrm{HB}$ per day for six weeks. After the end of the supplementation period, a $20 \mathrm{~km}$ run test was carried out, which showed statistically significant lower levels of both CK and LDH activity in the athletes regularly taking HMB. At the same time, in both groups, the peak CK level was recorded 24 hours after the $20 \mathrm{~km}$ run. (37). No similar results were obtained in our study. In the cited example, the supplementation period was three times longer.

The study protocol was based partly on the literature data. It was decided to use $6 \mathrm{~g}$ HMB to check if this dosage is sufficient to positively influence the analysed parameters in the limited period of the 12-day training camp. The fact that the plasma HMB half-life is $2.5 \mathrm{~h}$ when administered as calcium salt (Ca-HMB) and that taking $3 \mathrm{~g}$ of $\mathrm{Ca}-\mathrm{HMB}$ would result in the peak concentration of pure HMB in the bloodstream after 1 hour (38) contributed to Ca-HMB 
and AAKG being co-administered three times a day about 60 minutes before the physical activity. The use of higher doses than those most commonly found in the literature was aimed at optimising the rate at which the expected effects would appear (reduced level of the muscle cell damage markers, counteracted decrease in lower limb power, improved well-being and lower subjective feeling of effort intensity (sRPE)). Statistically significant differences were observed only for the countermovement jump.

\section{The limitations of the study}

In our opinion, it is also necessary to assess the effects of co-supplementation with HMB and AAKG after the end of the camp (training period), when after a period of complete rest, muscle power can significantly increase (supercompensation). Perhaps then other supplementation effects could also be observed.

\section{Conclusion}

The results of this study indicate that the daily co-supplementation with AAKG (8 g) and CaHMB (6 g) during the 12-day intensive training camp may prevent deterioration of lower limb muscle power measured by the countermovement jump test in the well-trained youth track and field athletes.

\section{Declarations}

Abbreviations: AAKG - L-arginine $\alpha$-ketoglutarate; HMB - $\beta$-hydroxy- $\beta$-methylbutyrate; HMB-Ca - calcium salt of $\beta$-hydroxy- $\beta$-methylbutyrate; SUP - supplemented group; PL placebo group; CMJ - countermovement jump; 1-RM: one-repetition maximum test; FFM free fat mass; $\mathrm{BF}$ - body fat; ARG- L-arginine; CK- creatine kinase, LDH - lactate dehydrogenase; mTOR - mammalian target of rapamycin/ phosphoinositide 3-kinase-related protein kinase; GH- growth hormone; IGF-1 - insulin-like growth factor-1; sRPE - session Ratings of Perceived Exertion; $\mathrm{VO}_{2}$ - oxygen consumption; TL - training load; 
437 Ethics approval and consent to participate: The study was approved by the Ethical 438 Committee of the University School of Physical Education in Katowice (Katowice, Poland; 439 Resolution No. 2/2018) and conformed to the ethical requirements of the 1975 Helsinki 440 Declaration. All participants were informed about risk and benefits associated with the study 441 and provided voluntary, written, informed consent.

442 Authors' contributions: Conceptualization: $\mathrm{PK}, \mathrm{AB}$ and $\mathrm{KK}$; methodology: $\mathrm{PK}, \mathrm{AB}$ and $443 \mathrm{KK}$; investigation and data collection: $\mathrm{PK}, \mathrm{AB}, \mathrm{KK}$ and $\mathrm{RJ}$, analysis and interpretation: $444 \mathrm{PK}, \mathrm{AB}, \mathrm{KK}$ and $\mathrm{MM}$; writing, original draft preparation: $\mathrm{PK}, \mathrm{AB}$ and $\mathrm{KK}$; writing and 445 editing: MM, EK, JB and TZ; supervision: PK. All authors have read and agreed to the 446 published version of the manuscript.

447 Acknowledgments: Not applicable

448 Consent for publication: Not applicable

449 Availability of data and materials: The datasets used and/or analyzed during the current 450 study are available from the corresponding author on reasonable request.

451 Competing interests: The authors declare that they have no competing interests.

452 Funding: This research received no external funding. 
Page $\mathbf{2 3}$ of $\mathbf{2 5}$

Attachment 1 - The well-being review sheet that was completed during the study (39).

\begin{tabular}{|c|c|c|c|c|c|}
\hline 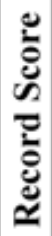 & & & & & \\
\hline- & 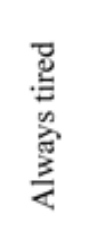 & 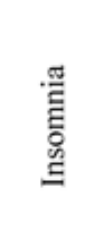 & 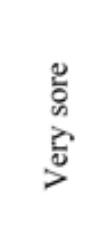 & 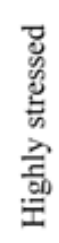 & 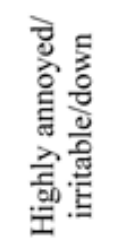 \\
\hline$N$ & 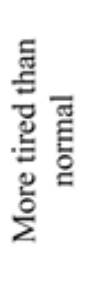 & 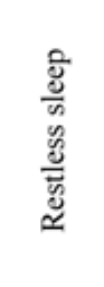 & 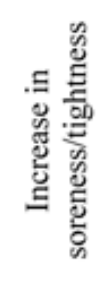 & 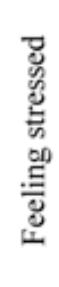 & 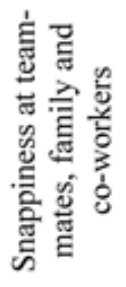 \\
\hline$m$ & $\begin{array}{l}\overline{\text { IJ }} \\
\text { E् } \\
\text { Z }\end{array}$ & 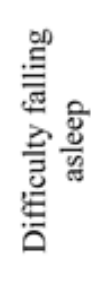 & $\begin{array}{l}\overline{\widetilde{J}} \\
\text { E् } \\
\text { Z }\end{array}$ & $\begin{array}{l}\overline{\mathrm{W}} \\
\overline{\mathrm{E}} \\
\mathrm{Z}\end{array}$ & 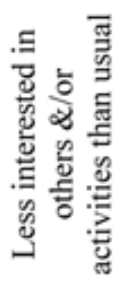 \\
\hline$\vec{T}$ & 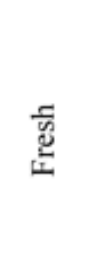 & $\begin{array}{l}\bar{\delta} \\
\text { S. }\end{array}$ & 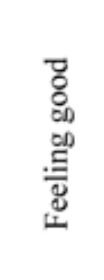 & 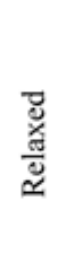 & 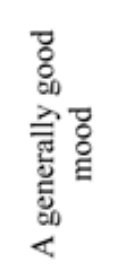 \\
\hline in & 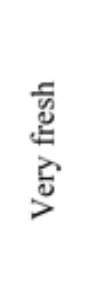 & 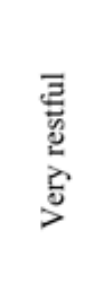 & 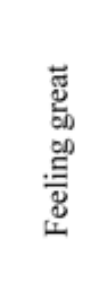 & 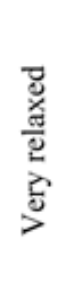 & 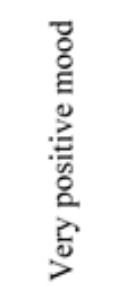 \\
\hline & 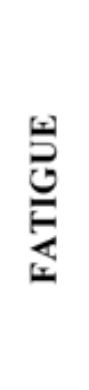 & 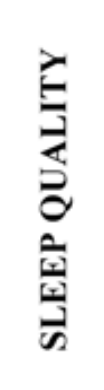 & 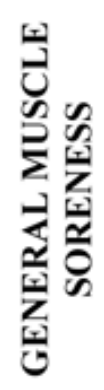 & 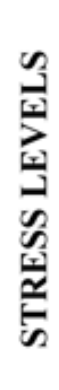 & 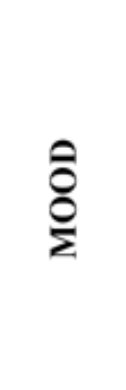 \\
\hline
\end{tabular}


Page $\mathbf{2 4}$ of $\mathbf{2 5}$

1 Position of Dietitians of Canada, the Academy of Nutrition and Dietetics and the American College of Sports Medicine, 2016

2 Campbell BI, La Bounty PM, Roberts M. The ergogenic potential of arginine. J Int Soc Sports Nutr. 2004 Dec 31;1(2):35-8.

3 Nissen S, Sharp R, Ray M, Rathmacher JA, Rice D, Fuller JC Jr, et al. Effect of leucine metabolite beta-hydroxybeta-methylbutyrate on muscle metabolism during resistance-exercise training. J Appl Physiol. 1996 Nov;81(5):2095-104.

4 Asadi A, Arazi H, Suzuki K. Effects of $\beta$-Hydroxy- $\beta$-methylbutyrate-free Acid Supplementation on Strength, Power and Hormonal Adaptations Following Resistance Training. Nutrients [Internet]. 2017 Dec 2;9(12). Available from: http://dx.doi.org/10.3390/nu9121316

5 Panton LB, Rathmacher JA, Baier S, Nissen S. Nutritional supplementation of the leucine metabolite betahydroxy-beta-methylbutyrate (hmb) during resistance training. Nutrition. 2000 Sep;16(9):734-9.

6 Wilson JM, Lowery RP, Joy JM, Andersen JC, Wilson SMC, Stout JR, et al. The effects of 12 weeks of betahydroxy-beta-methylbutyrate free acid supplementation on muscle mass, strength, and power in resistancetrained individuals: a randomized, double-blind, placebo-controlled study. Eur J Appl Physiol. 2014 Jun;114(6):1217-27.

7 Kreider RB, Ferreira MP, Greenwood M, Wilson M, Grindstaff P, Plisk S, et al. Effects of Calcium $\beta$-HMB Supplementation During Training on Markers of Catabolism, Body Composition, Strength and Sprint Performance. 2000 [cited 2020 Jul 23]; Available from: http://digitalcommons.wayne.edu/nfsfrp/7

8 Durkalec-Michalski K, Jeszka J, Podgórski T. The Effect of a 12-Week Beta-hydroxy-beta-methylbutyrate (HMB) Supplementation on Highly-Trained Combat Sports Athletes: A Randomised, Double-Blind, Placebo-Controlled Crossover Study. Nutrients [Internet]. 2017 Jul 14;9(7). Available from: http://dx.doi.org/10.3390/nu9070753

9 Yavuz HU, Turnagol H, Demirel AH. Pre-exercise arginine supplementation increases time to exhaustion in elite male wrestlers. Biol Sport. 2014 Aug;31(3):187-91.

10 Bailey SJ, Winyard PG, Vanhatalo A, Blackwell JR, DiMenna FJ, Wilkerson DP, et al. Acute L-arginine supplementation reduces the $\mathrm{O} 2$ cost of moderate-intensity exercise and enhances high-intensity exercise tolerance. J Appl Physiol. 2010 Nov;109(5):1394-403.

11 Campbell B, Roberts M, Kerksick C, Wilborn C, Marcello B, Taylor L, et al. Pharmacokinetics, safety, and effects on exercise performance of L-arginine alpha-ketoglutarate in trained adult men. Nutrition. 2006 Sep;22(9):87281.

12 Mor A, Atan T, Agaoglu SA, Ayyildiz M. Effect of arginine supplementation on footballers' anaerobic performance and recovery. Progress in Nutrition. 2018 Mar 29;20(1):104-12.

13 McConell GK, Huynh NN, Lee-Young RS, Canny BJ, Wadley GD. L-Arginine infusion increases glucose clearance during prolonged exercise in humans. Am J Physiol Endocrinol Metab. 2006 Jan;290(1):E60-6.

14 Nissen SL, Abumrad NN. Nutritional role of the leucine metabolite $\beta$-hydroxy $\beta$-methylbutyrate (HMB). J Nutr Biochem. 1997 Jun 1;8(6):300-11.

15 Smith HJ, Mukerji P, Tisdale MJ. Attenuation of proteasome-induced proteolysis in skeletal muscle by \{beta\}hydroxy-\{beta\}-methylbutyrate in cancer-induced muscle loss. Cancer Res. 2005 Jan 1;65(1):277-83.

16 Kornasio R, Riederer I, Butler-Browne G, Mouly V, Uni Z, Halevy O. Beta-hydroxy-beta-methylbutyrate (HMB) stimulates myogenic cell proliferation, differentiation and survival via the MAPK/ERK and PI3K/Akt pathways. Biochim Biophys Acta. 2009 May;1793(5):755-63.

17 Hooper SL, Mackinnon LT. Monitoring overtraining in athletes. Recommendations. Sports Med. 1995 Nov;20(5):321-7.

18 Buchheit M, Racinais S, Bilsborough JC, Bourdon PC, Voss SC, Hocking J, et al. Monitoring fitness, fatigue and running performance during a pre-season training camp in elite football players. J Sci Med Sport. 2013 Nov;16(6):550-5.

19 Haddad M, Stylianides G, Djaoui L, Dellal A, Chamari K. Session-RPE Method for Training Load Monitoring: Validity, Ecological Usefulness, and Influencing Factors. Front Neurosci. 2017 Nov 2;11:612.

20 Impellizzeri FM, Rampinini E, Coutts AJ, Sassi A, Marcora SM. Use of RPE-based training load in soccer. Med Sci Sports Exerc. 2004 Jun;36(6):1042-7.

21 Foster C, Florhaug JA, Franklin J, Gottschall L, Hrovatin LA, Parker S, et al. A new approach to monitoring exercise training. J Strength Cond Res. 2001 Feb;15(1):109-15. 
22 Abad-Colil F, Ramirez-Campillo R, Alvarez C, Castro M, Silva S, Izquierdo M. Effects of beta-hydroxy-betamethylbutyrate supplementation on physical performance of young players during an intensified soccer-training period: a short report. HMO. 2017;2017(5):91-6.

23 Kraemer WJ, French DN, Paxton NJ, Häkkinen K, Volek JS, Sebastianelli WJ, et al. Changes in exercise performance and hormonal concentrations over a big ten soccer season in starters and nonstarters. J Strength Cond Res. 2004 Feb;18(1):121-8.

24 Legg J, Pyne DB, Semple S, Ball N. Variability of Jump Kinetics Related to Training Load in Elite Female Basketball. Sports (Basel) [Internet]. 2017 Nov 4;5(4). Available from: http://dx.doi.org/10.3390/sports5040085

25 Nissen SL, Abumrad NN. Nutritional role of the leucine metabolite $\beta$-hydroxy $\beta$-methylbutyrate (HMB). J Nutr Biochem. 1997 Jun 1;8(6):300-11.

26 Wolin MS, Davidson CA, Kaminski PM, Fayngersh RP, Mohazzab-H KM. Oxidant--nitric oxide signalling mechanisms in vascular tissue. Biochemistry. $1998 \mathrm{Jul}$;63(7):810-6.

27 Durante W, Johnson FK, Johnson RA. Arginase: a critical regulator of nitric oxide synthesis and vascular function. Clin Exp Pharmacol Physiol. 2007 Sep;34(9):906-11.

28 Schaefer A, Piquard F, Geny B, Doutreleau S, Lampert E, Mettauer B, et al. L-arginine reduces exercise-induced increase in plasma lactate and ammonia. Int J Sports Med. 2002 Aug;23(6):403-7.

29 Ellis AC, Hunter GR, Goss AM, Gower BA. Oral Supplementation with Beta-Hydroxy-Beta-Methylbutyrate, Arginine, and Glutamine Improves Lean Body Mass in Healthy Older Adults. J Diet Suppl. 2019;16(3):281-93.

30 Kuipers H. Exercise-induced muscle damage. Int J Sports Med. 1994 Apr;15(3):132-5.

31 Alvares TS, Conte CA, Paschoalin VMF, Silva JT, Meirelles C de M, Bhambhani YN, et al. Acute I-arginine supplementation increases muscle blood volume but not strength performance. Appl Physiol Nutr Metab. 2012 Feb;37(1):115-26.

32 MacLeod CL. Regulation of cationic amino acid transporter (CAT) gene expression. Biochem Soc Trans. 1996 Aug;24(3):846-52.

33 Fuller JC Jr, Sharp RL, Angus HF, Baier SM, Rathmacher JA. Free acid gel form of $\beta$-hydroxy- $\beta$-methylbutyrate (HMB) improves $\mathrm{HMB}$ clearance from plasma in human subjects compared with the calcium HMB salt. Br J Nutr. 2011 Feb;105(3):367-72.

34 Gallagher PM, Carrithers JA, Godard MP, Schulze KE, Trappe SW. Beta-hydroxy-beta-methylbutyrate ingestion, Part I: effects on strength and fat free mass. Med Sci Sports Exerc. 2000 Dec;32(12):2109-15.

35 Wilson JM, Fitschen PJ, Campbell B, Wilson GJ, Zanchi N, Taylor L, et al. International Society of Sports Nutrition Position Stand: beta-hydroxy-beta-methylbutyrate (HMB). J Int Soc Sports Nutr. 2013 Feb 2;10(1):6.

36 Zanchi NE, Gerlinger-Romero F, Guimarães-Ferreira L, de Siqueira Filho MA, Felitti V, Lira FS, et al. HMB supplementation: clinical and athletic performance-related effects and mechanisms of action. Amino Acids. 2011 Apr;40(4):1015-25.

37 Knitter AE, Panton L, Rathmacher JA, Petersen A, Sharp R. Effects of beta-hydroxy-beta-methylbutyrate on muscle damage after a prolonged run. J Appl Physiol. 2000 Oct;89(4):1340-4.

38 Vukovich MD, Slater G, Macchi MB, Turner MJ, Fallon K, Boston T, et al. beta-hydroxy-beta-methylbutyrate (HMB) kinetics and the influence of glucose ingestion in humans. J Nutr Biochem. 2001 Nov;12(11):631-9.

39 McLean BD, Coutts AJ, Kelly V, McGuigan MR, Cormack SJ. Neuromuscular, endocrine, and perceptual fatigue responses during different length between-match microcycles in professional rugby league players. Int J Sports Physiol Perform. 2010 Sep;5(3):367-83. 
Figures

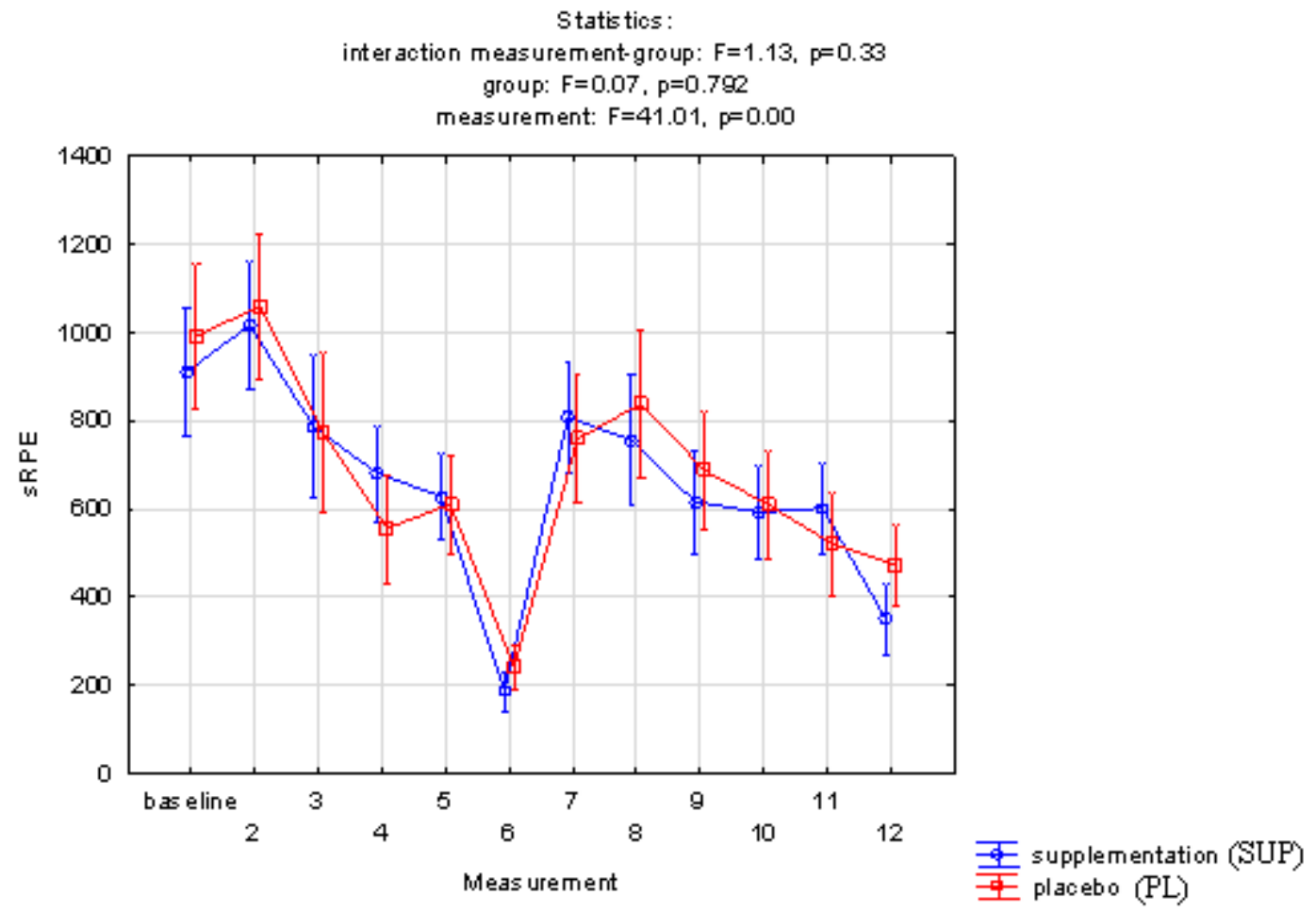

Figure 1. Changes in SRPE during trening in the SUP and PL group

Figure 1

Changes in SRPE during trening in the SUP and PL group. 
Statistics:

inter action group-measurement: $F=0,35, p=0,87$

group: $\mathrm{F}=0.00, \mathrm{p}=0,997$

meas urements: $F=38.09, p=0.00$

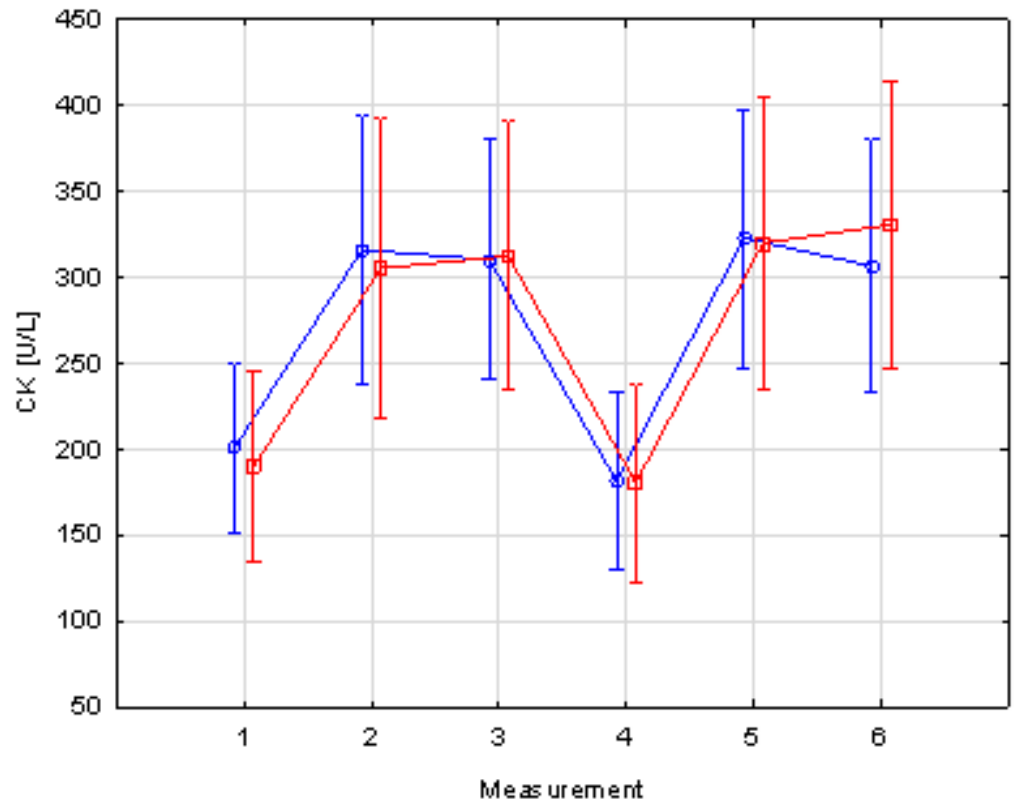

平 supplementation (SUP)
흐 placebo (PL)

Figure 2. Changes in $\mathrm{CK}$ during training in the $\mathrm{SUP}$ and $\mathrm{PL}$ group.

\section{Figure 2}

Changes in CK during trening in the SUP and PL group.

\section{Statis tics:}

interaction meas urement-group: $F=2.04, p=0.07$

group: $F=0.13, p=0.71$

meas urement: $F=38.09, p=0.00$

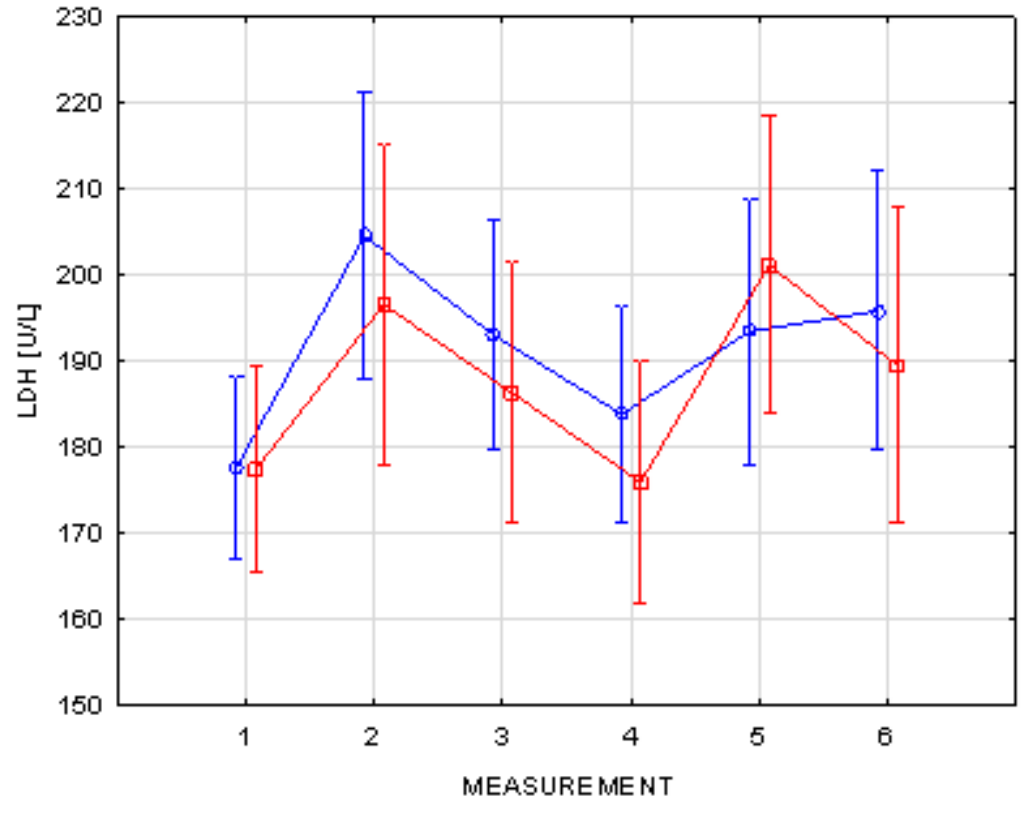

Figures 3. Changes in $\mathrm{LDH}$ during training in the SU and PL group. 
Figure 3

Changes in LDH during trening in the SU and PL group.

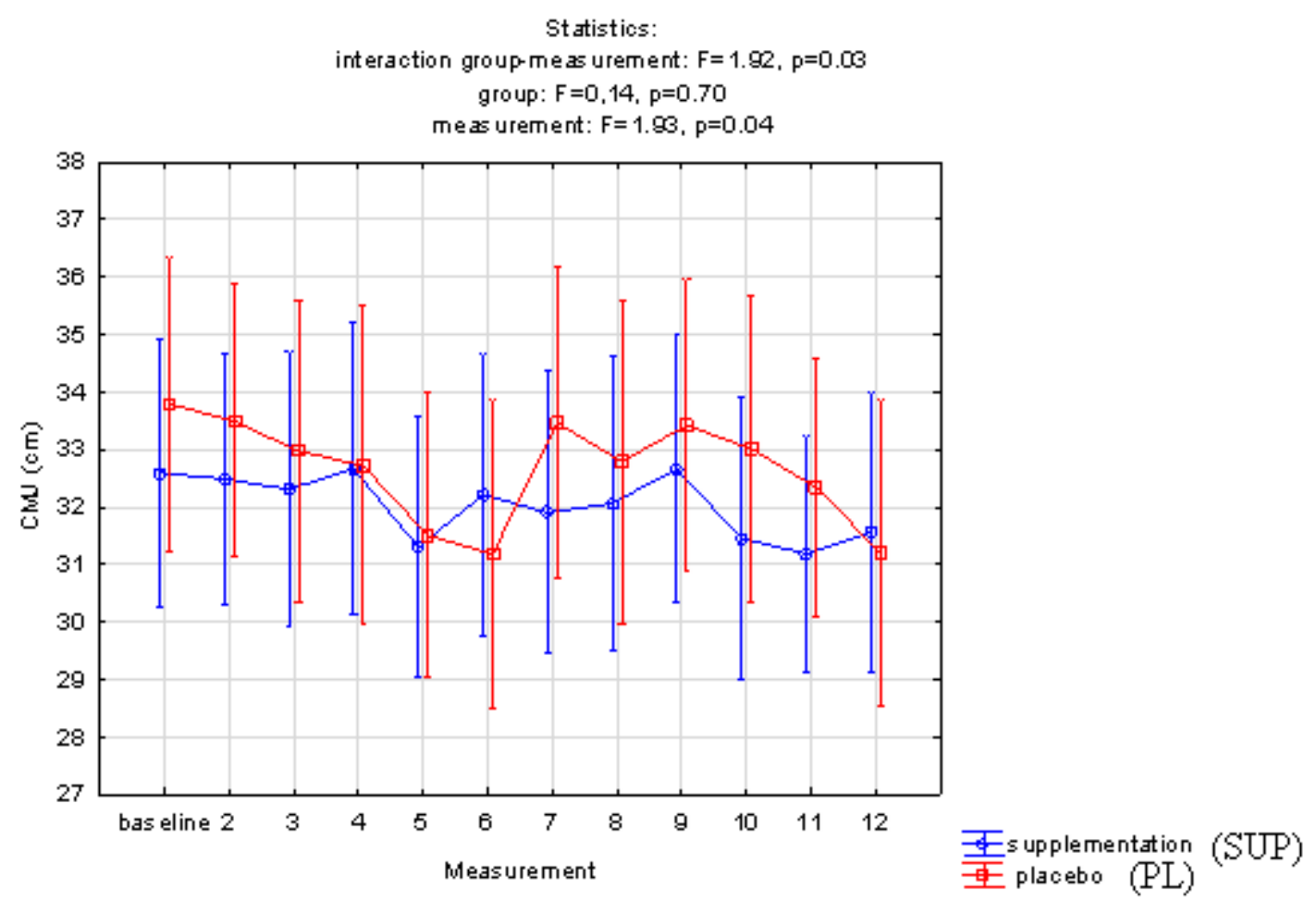

Figure 4. Changes in $\mathrm{CMJ}$ during training in the SUP and PL group.

\section{Figure 4}

Changes in CMJ during trening in the SUP and PL group. 
Statistics:

inter action meas urement-group: $F=1.39, p=0.17$

group: $F=0.12, p=0.73$

measurement: $F=6.62, p=0.00$

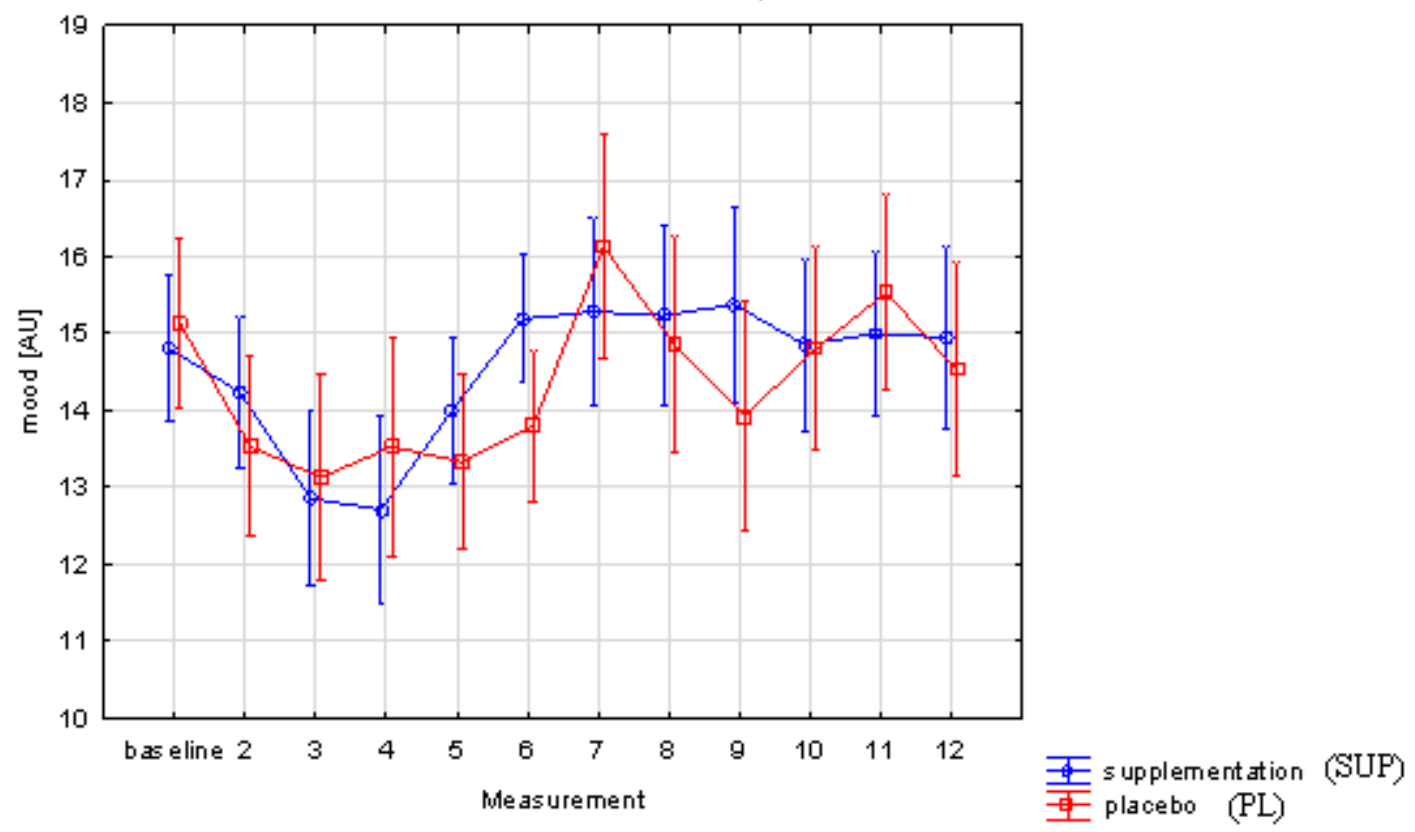

Figure 5. Changes in mood during training in the SUP and PL group

Figure 5

Changes in mood during trening in the SUP and PL group. 